\title{
ÜÇ BOYUTLU HÜCRE OLUŞTURMA PROBLEMİNE ÇOK AMAÇLI BİR ÇÖZÜM YAKLAŞIMI
}

\author{
Feriştah ÖZÇELİK ${ }^{*}$, Tuğba SARAÇ² \\ ${ }^{1}$ Eskişehir Osmangazi Üniversitesi, Mühendislik Mimarlık Fakültesi, Endüstri Mühendisliği Bölümü, Eskişehir \\ ORCID No : http://orcid.org/0000-0003-0329-203X \\ ${ }^{2}$ Eskişehir Osmangazi Üniversitesi, Mühendislik Mimarlık Fakültesi, Endüstri Mühendisliği Bölümü, Eskișehir \\ ORCID No : http://orcid.org/0000-0002-8115-3206
}

\begin{tabular}{|c|c|}
\hline Anahtar Kelimeler & Öz \\
\hline $\begin{array}{l}\text { Üç boyutlu hücre oluşturma } \\
\text { problemi, } \\
\text { Çok amaçlı programlama, } \\
\text { Genişletilmiş ع-kısıt yöntemi }\end{array}$ & $\begin{array}{l}\text { Üç boyutlu hücre oluşturma problemi, parça, makine ve işçi gruplarının oluşturulması } \\
\text { ve bu grupların hangi hücrelere atanacağının belirlenmesi problemidir. Bu problemin } \\
\text { temel amaçları, hücre dışı ve kullanılmayan eleman sayılarının enküçüklenmesidir. Bu } \\
\text { konuda literatürde yer alan çalışmaların önemli bir bölümünde bu iki amacın } \\
\text { toplandığı ve problemin tek amaçlı olarak ele alındığı görülmektedir. Bu çalışmada, üç } \\
\text { boyutlu hücre oluşturma problemi çok amaçlı olarak ele alınmıştır. Amaçların } \\
\text { birleştirilmesinde genişletilmiş ع-kısıt yöntemi kullanılmıştır. Elde edilen çözümler, } \\
\text { literatürdeki sonuçlarla karşlaştırılmış ve kullanılan problem seti için } 30 \text { yeni baskın } \\
\text { çözüm elde edilmiștir. }\end{array}$ \\
\hline
\end{tabular}

\section{A MULTI-OBJECTIVE SOLUTION APPROACH TO THREE DIMENSIONAL CELL FORMATION PROBLEM}

\begin{tabular}{|c|c|}
\hline Keywords & Abstract \\
\hline $\begin{array}{l}\text { Three dimensional cell } \\
\text { formation problem, } \\
\text { Multi-objective } \\
\text { programming, } \\
\text { Augmenteds-constraint } \\
\text { method }\end{array}$ & $\begin{array}{l}\text { Three-dimensional cell formation problem deals with grouping the parts, machines and } \\
\text { workers together and assigning these groups to the cells. The main objectives of this } \\
\text { problem are to minimize the number of exceptional elements and voids. It is seen that in } \\
\text { most of the studies in the literature on this subject, these two objectives are summed } \\
\text { and the problem is taken in a single objective manner. In this study three dimensional } \\
\text { cell formation problem is considered as a multi-objective problem. Augmented } \varepsilon- \\
\text { constraint method is used to scalarize the objectives. Obtained solutions are compared } \\
\text { with the results from the literature and } 30 \text { new non-dominant solutions are found for } \\
\text { the used test set. }\end{array}$ \\
\hline Araştırma Makalesi & Research Article \\
\hline Başvuru Tarihi & Submission Date \\
\hline Kabul Tarihi & Accepted Date \\
\hline
\end{tabular}

* Sorumlu yazar; e-posta : $\underline{\text { fdurmaz@ogu.edu.tr }}$

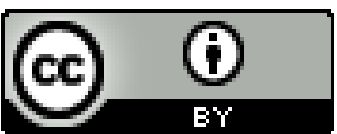

$\mathrm{Bu}$ eser, Creative Commons Attribution License (http://creativecommons.org/licenses/by/4.0/) hükümlerine göre açlk erișimli bir makaledir.

This is an open access article under the terms of the Creative Commons Attribution License (http://creativecommons.org/licenses/by/4.0/). 


\section{Giriş}

Hücresel üretim, grup teknolojisi felsefesine dayanır ve benzer parçaların birlikte üretilmesini amaçlar. Hücre oluşturma problemi, hücresel üretimin ilk ve en önemli aşamasıdır. Bu problem, parça ailelerinin belirlenmesi ve üretilmesi için gerekli olan kaynaklarla birlikte hücrelere atanmasıdır. Hücre oluşturma problemi ile ilgili literatürde pek çok çalışma olmasına rağmen bunların çoğunluğu sadece makine ve parçaları dikkate almaktadır. Uygulamada ise genellikle sadece makinelerin ve parçaların gruplandırılması yeterli olmamaktadır. Üretkenliği arttırabilmek için hücrelerin oluşturulması esnasında işçilerin de dikkate alınması kritik bir öneme sahiptir. Min ve Shin (1993), parça, makine ve işçilerin bir arada ele alındığı üç boyutlu (kübik) hücre oluşturma problemini ilk kez tanımlamıștır. Mahdavi, Aalaei, Paydar ve Solimanpur (2012), üç boyutlu hücre oluşturma probleminde hücre dışı eleman ve kullanılmayan eleman sayılarını enküçüklemek amacıyla bir matematiksel model önermişlerdir.

Aalaei ve Shavazipour (2013), çalışmalarında en etkin hücre tasarımının belirlenmesi amacıyla veri zarflama analizi (VZA) kullanmışlardır. VZA'da çıktı değişkeni olarak ortalama makine kullanımı, ortalama işçi kullanımı ve girdi değişkenleri olarak ürün sayısı ve makine sayısı, işçi sayısı, parça sayısı ve talep seviyeleri ele alınmıştır. Hücrelerin etkinlik değerlerinin hesaplanmasında Tchebycheff normu kullanılmıştır.

Bootaki, Mahdavi ve Paydar (2014) çalışmalarında hücreler arası taşımaların enküçüklenmesi ve parçakalite indeksinin enbüyüklenmesi amaçlarını dikkate alan üç boyutlu hücre oluşturma problemini ele almışlardır. Problemin çözümü için genetik algoritma ve genişletilmiş $\varepsilon$-kısıt yönteminin birlikte kullanıldığı melez bir algoritma geliştirmişlerdir.

Bootaki, Mahdavi ve Paydar (2016), üretim hücrelerinin uzmanlık ve ilgi seviyelerini arttırmayı hedeflemişlerdir. $\mathrm{Bu}$ amaçla, işçi-makine ve işçi-işçi temas matrislerinin her ikisinin de kullanılmayan eleman sayılarını enküçükleyen bir matematiksel model geliştirmişlerdir. Modelin çözümü için genişletilmiş $\varepsilon$-kısıt yöntemi ve büyük boyutlu problemlerin çözümü için de bir NSGA-II algoritması önermişlerdir.

Buruk Şahin ve Alpay (2016), kübik hücre oluşturma probleminin çözümü için bir genetik algoritma geliştirmişlerdir.

Mehdizadeh, Niaki ve Rahimi (2016), hücre oluşturma ve üretim planlama problemlerini aynı anda dikkate alan çok amaçlı karma tamsayılı bir matematiksel model geliştirmişlerdir. Problemin çözümü için bir çok amaçlı titreşim sönümlemesi optimizasyon algoritması önermişlerdir.

Feng, Da, Xi, Pan ve Xia (2017), hücre oluşturma ve ișçi atama problemlerini birlikte ele almış ve problem için bir matematiksel model geliştirmişlerdir. Çözüm yöntemi olarak parçacık sürü optimizasyon algoritmasının ve doğrusal programlamanın birlikte çalıştığı melez bir yöntem önermişlerdir.

Bagheri, Kermanshahi, Safaei ve Paydar(2019), işçi tercihlerinin dikkate alındığı dinamik hücre oluşturma problemi için toplam gruplama etkinliğini enbüyükleme ve toplam maliyeti ve hücrede birlikte çalışmak istemeyen toplam işçi sayısını enküçükleme amaçlarına sahip bir hedef programlama modeli önermişlerdir.

Fahmy (2019), çalışmasında hücre oluşturma, hücre yerleşimi ve işçi atama problemlerini birlikte ele alan bütünleşik bir karma tamsayılı doğrusal programlama (MILP) modeli geliştirmiştir. Çalışanların farklı yetenek düzeylerine sahip olduğu ve işçi yükü, manuel iş yükü ve malzeme taşıma görevlerine bağlı olduğu varsayılmıştır. Problemin çözümü için bir genetik algoritma önerilmiştir.

Bouaziz, Berghida ve Lemouari(2020), genelleştirilmiş üç boyutlu hücre oluşturma problemi için çok amaçlı bir matematiksel model önermişlerdir. Ele alınan amaçlar; hücreler arası malzeme aktarma maliyetinin, hücre içi malzeme aktarma maliyetinin ve işçi hareket maliyetinin enküçüklenmesidir. Problemin çözümü için kesikli çiçek tozlaşma algoritması önermişlerdir.

Gökdaş ve Özçelik (2020), parça-makine-işçi temas matrisini dikkate alan üç boyutlu hücre oluşturma probleminin çözümü için arı algoritması geliştirmişlerdir. Geliştirilen algoritma, hücre sayısının önceden bilindiği ve sabit olduğu literatürdeki diğer çalışmalardan farklı olarak, eniyi hücre sayısını da belirleyebilmektedir.

Hücre oluşturma probleminin temel amaçları, hücre dışı ve kullanılmayan eleman sayılarının enküçüklenmesidir. Hücre dışı elemanlar, parça, parçanın işlem göreceği makine ve parçayı ilgili makinede işleyecek işçinin aynı hücreye atanmaması durumunda ortaya çıkmaktadır. $\mathrm{Bu}$ durumda ya parçanın ya da işçinin başka bir hücreye taşınması söz konusu olacaktır (Gökdaş ve Özçelik, 2020). Kullanılmayan elemanlar ise parçanın atandı̆̆ı hücrede yer alan makine ve/veya işçiye gereksinim duyulmaması durumunda ortaya çıkmaktadır. $\mathrm{Bu}$ da kapasite kullanım oranlarının düşmesine yol açtığından hücre kullanım performansını olumsuz yönde etkilemektedir. Bu nedenle her iki amaç birlikte ele alınmalıdır. Literatürde bu iki amacı dikkate alan çalışmaların çoğunda (Mahdavi, ve diğ., 2012);Feng ve 
diğ. (2017);Bouaziz ve diğ. (2020);Gökdaş ve Özçelik (2020)) ağırlıklı toplam yönteminin kullanıldığı ve ağırlıkların eșit kabul edildiği görülmüștür. Oysa karar verici açısından bu iki amaç her zaman eşit ağırlıklı olmayabilir. $\mathrm{Bu}$ çalışmada karar vericiye farklı çözümler sunabilmek için genişletilmiş $\varepsilon$-kısıt yöntemi kullanılmıştır. Literatürde genişletilmiş $\varepsilon$-kısıt yöntemini kullanan çalışmalara (Bootaki ve diğ., 2014); Bootaki ve diğ., 2016)) bakıldığında ise bu çalışmada ele alınan amaçlardan farklı amaçları dikkate aldıkları görülmektedir. Sonuç olarak bu çalışma, hücre dışı ve kullanılmayan eleman sayılarının enküçüklenmesi amaçlarını birlikte ele alan ve genişletişmiş $\varepsilon$-kısıt yöntemini kullanan ilk çalışmadır.

İzleyen bölümde ele alınan problemin tanımı ve matematiksel modeli verilmiştir. Üçüncü bölümde kullanılan amaç birleștirme yöntemi ve önerilen model sunulmuştur. Dördüncü bölümde deneysel sonuçlar, son bölümde ise sonuç ve öneriler tartışılmıştır.

\section{Problem Tanımı ve Matematiksel Model}

$\alpha$ adet parça, $\beta$ adet makine ve $\gamma$ adet işçinin $\delta$ adet hücreye atanması gerekmektedir. $\mathrm{Bu}$ atamayı gerçekleştirebilmek için üç boyutlu parça-makine-işçi temas matrisi kullanılmıştır. Matrisin ilgili elemanı, eğer ilgili parça, ilgili makinede ilgili işçi ile işlenebiliyorsa 1 , diğer durumda 0 değerini almaktadır. Makine ve işçiler için kapasite kısıtının olmadığı ve her işçinin her makinede çalışamadığı varsayılmıştır. Amaç fonksiyonları hücre dişı ve kullanılmayan eleman sayılarının enküçüklenmesidir. Ele alınan problemin matematiksel modeli (M) (Mahdavi ve diğ., 2012) bu modele ait kümeler, indisler, parametreler, karar değişkenleri, amaç fonksiyonları ve kısıtlar aşağıda verilmiştir.

\section{Kümeler ve İndisler:}

$P$ : parça tipi kümesi, $P=\{1,2, \ldots, \alpha\}$

$M$ : makina tipi kümesi, $M=\{1,2, \ldots, \beta\}$

$W$ : işçi tipi kümesi $W=\{1,2, \ldots, \gamma\}$

$K$ : hücre kümesi $K=\{1,2, \ldots, \delta\}$

$p \in P$ parça indisi

$m \in M$ makina indisi

$w \in W$ işçi indisi

$k \in K$ hücre indisi

\section{Parametreler:}

$r_{p m w}$ : parça $p$, işçi $w$ ile makine $m$ 'de işlenebiliyorsa 1 ; diğer durumda 0

$a_{p m}$ : parça $p^{\prime}$ nin makine $m$ 'de işlemi varsa 1 ; diğer durumda 0

$L M$ : hücrelerin makine sayısı için alt sınır
$L P$ : hücrelerin parça sayısı için alt sınır

$L W$ : hücrelerin işçi sayısı için alt sınır

\section{Karar değişkenleri:}

$x_{m k}$ : makine $m$, hücre $k^{\prime}$ ya atanmışsa 1 ; diğer durumda 0

$y_{p k}$ : parça $p$, hücre $k$ 'ya atanmışsa 1 ; diğer durumda 0

$z_{w k}$ : işçi $w$, hücre $k^{\prime}$ ya atanmışsa 1 ; diğer durumda 0

$d_{p m w k}:$ parça $p$, makine $m$ ile işçi $w$ tarafından hücre $k^{\prime}$ da işleniyorsa 1; diğer durumda 0

$E_{p m w k}$ : amaç fonksiyonunun doğrusallaştırılmasında kullanılan 0-1 değișken

$$
E_{p m w k}=x_{m k} d_{p m w k}
$$

$F_{p m w k}$ : amaç fonksiyonlarının doğrusallaştırılmasında kullanılan 0-1 değişken

$$
F_{p m w k}=x_{m k} y_{p k} Z_{w k}
$$

$S_{\text {pmwk }}$ : amaç fonksiyonlarının doğrusallaştırılmasında kullanılan 0-1 değişken

$$
S_{p m w k}=F_{p m w k} d_{p m w k}
$$

$H_{p m w k}$ : amaç fonksiyonlarının doğrusallaştırılmasında kullanılan 0-1 değişken

$$
H_{p m w k}=y_{p k} E_{p m w k}
$$

$G_{p m w k}$ : amaç fonksiyonlarının doğrusallaştırılmasında kullanılan 0-1 değişken

$$
G_{p m w k}=z_{w k} E_{p m w k}
$$

(M):

Kisitlar:

$$
\begin{array}{lc}
\sum_{k=1}^{\delta} Z_{w k}=1 & \forall w \\
\sum_{k=1}^{\delta} y_{p k}=1 & \forall p \\
\sum_{k=1}^{\delta} x_{m k}=1 & \forall m \\
\sum_{w=1}^{\gamma} Z_{w k} \geq L W & \forall k \\
\sum_{p=1}^{\alpha} y_{p k} \geq L P & \forall k \\
\sum_{m=1}^{\beta} X_{m k} \geq L M & \forall k
\end{array}
$$




$$
\begin{aligned}
& d_{p m w k} \leq r_{p m w} x_{m k} \quad \forall p, m, w, k \\
& \sum_{k=1}^{\delta} \sum_{w=1}^{\gamma} d_{p m w k}=a_{p m} \quad \forall p, m \\
& E_{p m w k} \geq x_{m k}+d_{p m w k}-1,5 \quad \forall p, m, w, k \\
& F_{p m w k} \geq x_{m k}+y_{p k}+z_{w k}-2,5 \quad \forall p, m, w, k \\
& S_{p m w k} \geq F_{p m w k}+d_{p m w k}-1,5 \quad \forall p, m, w, k \\
& 1,5 S_{p m w k} \leq F_{p m w k}+d_{p m w k} \quad \forall p, m, w, k \\
& H_{p m w k} \geq y_{p k}+E_{p m w k}-1,5 \quad \forall p, m, w, k \\
& 1,5 H_{p m w k} \leq y_{p k}+E_{p m w k} \quad \forall p, m, w, k \\
& G_{p m w k} \geq z_{w k}+E_{p m w k}-1,5 \quad \forall p, m, w, k \\
& 1,5 G_{p m w k} \leq z_{w k}+E_{p m w k} \quad \forall p, m, w, k \\
& x_{m k}, y_{i k}, z_{w k}, d_{p m w k}, E_{p m w k}, F_{p m w k}, G_{p m w k}, S_{p m w k}, \\
& H_{p m w k} \in\{0,1\} \quad \forall p, m, w, k
\end{aligned}
$$

\section{Amaç Fonksiyonları:}

$$
\begin{array}{r}
f_{1}=\text { enk } \sum_{p=1}^{\alpha} \sum_{m=1}^{\beta} \sum_{w=1}^{\gamma} \sum_{k=1}^{\delta}\left[2 E_{p m w k}-H_{p m w k}\right. \\
\left.-G_{p m w k}\right] \\
f_{2}=\operatorname{enk} \sum_{p=1}^{\alpha} \sum_{m=1}^{\beta} \sum_{w=1}^{\gamma} \sum_{k=1}^{\delta}\left[F_{p m w k}-S_{p m w k}\right]
\end{array}
$$

Eşitlik (1) her işçinin yalnızca bir hücreye atanmasını sağlar. Eşitlik (2), her parça tipinin yalnızca bir hücreye atanmasını ifade eder. Eşitlik (3), her makine tipinin yalnızca bir hücreye atanmasını garanti eder. Eşitlik (4), her hücreye işçi sayısı alt sınırına eșit ya da daha fazla sayıda işçi atanmasını sağlar. Eşitlik (5), her hücreye parça sayısı alt sınırına eşit ya da daha fazla sayıda parça atanmasını sağlar. Eşitlik (6), her hücreye makine sayısı alt sınırına eșit ya da daha fazla sayıda makine atanmasını sağlar. Eşitlik (7)-(8), $d_{p m w k}$ karar değişkeninin değerinin uygunluk kısıtlarını dikkate alarak hesaplanmasını sağlar. Eşitlik (9)-(16) amaç fonksiyonlarının doğrusallaştırılmasında kullanılan kısıtlardır. Eşitlik (17) karar değişkenlerine ait işaret kısıtlarıdır. Birinci amaç fonksiyonu $\left(f_{1}\right)$ (18) hücre dışı eleman sayısının enküçüklenmesidir. İkinci amaç fonksiyonu $\left(f_{2}\right)$ (19) kullanılmayan eleman sayısının enküçüklenmesidir.

Bu çalışmada araştırma ve yayın etiğine uyulmuştur.

\section{3. Üç Boyutlu Hücre Oluşturma Problemi için Genişletilmiş $\varepsilon$-kısıt Yöntemi}

$f(x)$, tüm amaçları enküçükleme şeklinde olan çok amaçlı bir matematiksel modelin $x$ çözümüne (x€ $X)$ karşı gelen amaç vektörü iken; $f(x) \leq f\left(x^{*}\right)$ şartını sağlayan bir $x$ çözümü bulunamıyor ise, $x^{*}$, etkin çözüm (Pareto-eniyi çözüm), $f\left(x^{*}\right)$ ise baskın nokta olarak isimlendirilir. $f(x)<f\left(x^{*}\right)$ şartını sağlayan bir $x$ çözümü bulunamıor ise, $x^{*}$, zayıf etkin çözüm, $f\left(x^{*}\right)$ ise zayıfbaskın nokta olarak isimlendirilir. Problemin $p$ adet amacı var iken, ideal noktasıy ${ }^{\mathrm{I}}=\left(\mathrm{y}_{1}^{\mathrm{I}}, \ldots, \mathrm{y}_{\mathrm{p}}^{\mathrm{I}}\right)$ eşitlik (20)'de verildiği şekilde hesaplanır.

$y_{k}^{\mathrm{I}}=\operatorname{enk}_{\mathrm{x} \in \mathrm{X}} \mathrm{f}_{\mathrm{k}}(\mathrm{x}) \quad \mathrm{k}=1, \ldots, \mathrm{p}$

Problemin nadir noktası $\mathrm{y}^{\mathrm{N}}=\left(\mathrm{y}_{1}^{\mathrm{N}}, \ldots, \mathrm{y}_{\mathrm{p}}^{\mathrm{N}}\right)$ iseeşitlik (21)'de verildiği gibi hesaplanır.

$\mathrm{y}_{\mathrm{k}}^{\mathrm{N}}=\operatorname{enb}_{\mathrm{x} \in \mathrm{X}_{\mathrm{E}}} \mathrm{f}_{\mathrm{k}}(\mathrm{x}) \quad \mathrm{k}=1, \ldots, \mathrm{p}$

Burada $X_{E}$ etkin çözüm kümesini göstermektedir.

Çok amaçlı problemleri ele alan çalışmaların çoğunda amaçların doğrusal bileşimi kullanılarak problem tek amaçlı yapıya dönüştürülmektedir. Ancak bu yöntem kullanıldığında görüntü kümesinin dışbükey olmayan bölgelerinde yer alan baskın noktaların elde edilebilmesi mümkün değildir. Tamsayılı problemlerin uygun çözüm ve görüntü kümelerinin dışbükey olmadığı göz önünde bulundurularak, bu çalışmada görüntü kümesinin dışbükey olmayan bölgelerinde yer alan baskın noktaları da bulabilen genişletilmiş $\varepsilon$-kısıt yöntemi kullanılmıştır.

$\varepsilon$-kısıt yöntemi, çok amaçlı problemlerin amaç fonksiyonlarından birisinin amaç fonksiyonu olarak belirlendiği diğer amaç fonksiyonlarının ise $\varepsilon$-eşitsizlik kısıtları olarak modele eklendiği bir tek amaca dönüştürme yöntemidir. Genişletilmiş $\varepsilon$-kısıt (Augmented $\varepsilon$-constraint-AEC) yöntemi, klasik $\varepsilon$-kısıt yönteminin zayıf pareto çözümler üretmesini önlemek amaciyla 2009 yılında Mavrotas tarafından geliştirilmiştir. $\mathrm{Bu}$ yöntemin klasik yöntemden iki önemli farkı, ödünleșme tablosunun olușturulması sırasında sözlüksel sıralama yaklaşımının kullanılması ve $\varepsilon$-kısıtların aylak/artık değişken eklenerek eşitlik kısıtına dönüştürülmesidir. Bu değişkenlerin amaç fonksiyonuna eklenmesiyle tüm amaçların dikkate alınabilmesi sağlandığından pareto çözümlerin elde edilebilmesi mümkün olabilmektedir. Ele alınan problemin genişletilmiş $\varepsilon$-kısıt yöntemi ile skalerleştirilmiş modeli (M-AEC) ve bu modelde kullanılan ek parametre ve karar değişkenleri aşağıda verilmiștir.

\section{Parametreler:}

$\varepsilon$ : Kullanılmayan eleman sayısının enküçüklenmesi amacına ait $\varepsilon$-kısıtın sağ taraf sabiti. 
$\mu$ : Çok küçük pozitif sayı (Bu çalışmada $10^{-6}$ olarak alınmıştır).

$f_{1}^{I}, f_{2}^{I}$ : İlk ve ikinci amaçların ideal değerleri

$f_{1}^{N}, f_{2}^{N}$ : İlk ve ikinci amaçların nadir değerleri

\section{Karar Değişkeni:}

a: Kullanılmayan eleman sayısının enküçüklenmesiamacına ait $\varepsilon$ kısıta eklenen aylak değişken.

(M-AEC):

Kisitlar:

(1) - (17)

$\sum_{p=1}^{\alpha} \sum_{m=1}^{\beta} \sum_{w=1}^{\gamma} \sum_{k=1}^{\delta}\left[F_{p m w k}-S_{p m w k}\right]+a=\varepsilon$

$a \geq 0$

Amaç fonksiyonu:

$f_{A E C}=\operatorname{enk}\left(\sum_{p=1}^{\alpha} \sum_{m=1}^{\beta} \sum_{w=1}^{\gamma} \sum_{k=1}^{\delta}\left[2 E_{p m w k}-H_{p m w k}-\right.\right.$

$\left.\left.G_{p m w k}\right]-\frac{\mu a}{f_{2}^{N}-f_{2}^{I}}\right)$

Ele alınan problemin genişletilmiş $\varepsilon$-kısıt yöntemi ile çözülebilmesi için izlenen adımlar aşağıda verilmiştir.

Adım 1: (M) modeli için ideal $f^{I}=\left(f_{1}^{I}, f_{2}^{I}\right)$ ve nadir $f^{N}=\left(f_{1}^{N}, f_{2}^{N}\right)$ noktaları hesapla. (Ödünleşme tablosunun sözlüksel sıralama yaklaşımı ile oluşturulması iki amaçlı problemler için ideal ve nadir noktaların hesaplanması ile aynı anlama gelmektedir.)

Adım 2: F baskın noktalar kümesi olmak üzere, $\left(f_{1}^{I}, f_{2}^{N}\right)$ noktasını kümenin ilk elemanı olarak ata. Ve $\varepsilon^{\prime}$ a başlangıç değerini ata. $\varepsilon=f_{2}^{N}$.

Adım 3: M-AEC modelini güncel $\varepsilon$ değeri için çöz. Elde edilen çözümü $\left(f_{1}^{*}, f_{2}^{*}\right), \mathrm{F}$ kümesine ekle. $\varepsilon=$ $\varepsilon-\Delta$ formülünü kullanarak $\varepsilon$ değerini güncelle. (Burada $\Delta=\left(f_{2}^{N}-f_{2}^{I}\right) / 50$ olarak alınmıştır.)

Adım 4: Ĕger $\varepsilon \geq f_{2}^{I}$ ise Adım 3'e git. Değilse DUR.

\section{Deneysel Sonuçlar}

Önerilen matematiksel model, literatürden alınan test problemleri kullanılarak çözülmüștür. Tüm testler Intel (R) Core (TM) i7- 5700HQ CPU@2.70 GH işlemcisi, 8 GB belleği ve Windows 10 işletim sistemine sahip bir bilgisayarda 30000 saniye süre limiti ile yapılmıştır. Matematiksel model GAMS 24.1.3 ile kodlanmış ve çözücü olarak Cplex kullanılmıștır.

Algoritmanın performansı Mahdavi ve diğ.'den (2012) alınan veri seti kullanılarak test edilmiştir. Veri setindeki problemlerin parça, makine ve işçi sayıları Tablo 1 'de verilmiştir. $L M, L W$ ve $L P$ parametrelerinin değerleri diğer çalışmalarda olduğu gibi 1 olarak kabul edilmiştir.

Tablo 1

\begin{tabular}{cccc}
\multicolumn{4}{c}{ Veri Setinin Özellikleri } \\
Problem & Parça sayısı & Makine sayısı & İşçi sayısı \\
\hline P1 & 4 & 4 & 4 \\
P2 & 5 & 4 & 5 \\
P3 & 6 & 5 & 5 \\
P4 & 10 & 7 & 4 \\
P5 & 10 & 7 & 6 \\
\hline
\end{tabular}

Tüm test problemlerinin ele alınan her bir hücre sayısı için ideal ve nadir noktaları hesaplanarak Tablo 2'de verilmiştir. Tablodan da görülebileceği gibi P1 probleminin hem 2 hücreli hem de 3 hücreli durumu için ideal ve nadir noktaları aynıdır. Bu nedenle bu problemler için farklı baskın noktalar bulmak mümkün değildir. Benzer şekilde P2 probleminin 3 hücreli ve P3 probleminin 4 hücreli olarak ele alındığı durumlar için de ideal ve nadir noktaları aynıdır.

Test problemlerinin M-AEC modeliyle çözülmesi ile elde edilen sonuçlar Tablo 3'te verilmiştir. Elde edilen sonuçlar, Mahdavi ve diğ., (2012) ve Gökdaş ve Özçelik'in (2020) sonuçları ile karşılaștırılmıștır. Kullanılan problem seti için literatürde erişilemeyen 30 yeni baskın çözüm elde edilmiștir.

Tablo 2

İdeal ve Nadir Noktalar

\begin{tabular}{|c|c|c|c|c|c|}
\hline \multirow{2}{*}{. } & \multirow[b]{2}{*}{$C$} & \multicolumn{2}{|c|}{ ideal nokta } & \multicolumn{2}{|c|}{ nadir nokta } \\
\hline & & $I_{1}$ & $I_{2}$ & $N_{1}$ & $\mathrm{~N}_{2}$ \\
\hline \multirow[t]{2}{*}{$\mathrm{P} 1$} & 2 & 3 & 4 & 3 & 4 \\
\hline & 3 & 5 & 1 & 5 & 1 \\
\hline \multirow[t]{2}{*}{ P2 } & 2 & 0 & 10 & 1 & 20 \\
\hline & 3 & 1 & 3 & 1 & 3 \\
\hline \multirow[t]{2}{*}{ P3 } & 2 & 0 & 14 & 4 & 24 \\
\hline & 4 & 4 & 1 & 4 & 1 \\
\hline \multirow[t]{3}{*}{ P4 } & 2 & 5 & 17 & 28 & 135 \\
\hline & 3 & 12 & 4 & 32 & 11 \\
\hline & 4 & 16 & 0 & 29 & 3 \\
\hline \multirow[t]{3}{*}{ P5 } & 3 & 1 & 11 & 17 & 30 \\
\hline & 4 & 2 & 7 & 10 & 22 \\
\hline & 5 & 4 & 3 & 5 & 8 \\
\hline
\end{tabular}


Tablo 3

Test Sonuçları

\begin{tabular}{|c|c|c|c|c|c|c|c|}
\hline & \multirow[b]{2}{*}{$C$} & \multicolumn{2}{|c|}{ Mahdavi vd., 2012} & \multicolumn{2}{|c|}{ Gökdaş ve Özçelik, 2020} & \multicolumn{2}{|c|}{ M-AEC } \\
\hline & & $f_{1}$ & $f_{2}$ & $f_{1}$ & $f_{2}$ & $f_{1}$ & $f_{2}$ \\
\hline \multirow[t]{2}{*}{ P1 } & 2 & 3 & 4 & 3 & 4 & 3 & 4 \\
\hline & 3 & - & - & 5 & 1 & 5 & 1 \\
\hline \multirow[t]{3}{*}{ P2 } & 2 & 1 & 10 & 1 & 10 & 1 & 10 \\
\hline & & - & - & - & - & 0 & 20 \\
\hline & 3 & - & - & 1 & 3 & 1 & 3 \\
\hline \multirow[t]{4}{*}{ P3 } & 2 & 4 & 14 & 4 & 14 & 4 & 14 \\
\hline & & - & - & - & - & 3 & 19 \\
\hline & & - & - & - & - & 0 & 24 \\
\hline & 4 & - & - & 4 & 1 & 4 & 1 \\
\hline \multirow[t]{18}{*}{ P4 } & 2 & - & - & - & - & 28 & 17 \\
\hline & & - & - & - & - & 20 & 18 \\
\hline & & 14 & 20 & 14 & 20 & 14 & 20 \\
\hline & & - & - & - & - & 11 & 26 \\
\hline & & - & - & - & - & 10 & 34 \\
\hline & & - & - & - & - & 9 & 42 \\
\hline & & - & - & - & - & 8 & 75 \\
\hline & & - & - & - & - & 7 & 84 \\
\hline & & - & - & - & - & 6 & 119 \\
\hline & & - & - & - & - & 5 & 135 \\
\hline & 3 & - & - & - & - & 30 & 5 \\
\hline & & - & - & - & - & 14 & 6 \\
\hline & & - & - & 13 & 7 & 13 & 7 \\
\hline & & - & - & - & - & 12 & 11 \\
\hline & 4 & - & - & - & - & 29 & 0 \\
\hline & & - & - & - & - & 18 & 1 \\
\hline & & - & - & 17 & 2 & 17 & 2 \\
\hline & & - & - & - & - & 16 & 3 \\
\hline \multirow[t]{15}{*}{ P5 } & 3 & - & - & - & - & 17 & 11 \\
\hline & & - & - & - & - & 11 & 15 \\
\hline & & - & - & - & - & 10 & 16 \\
\hline & & - & - & - & - & 7 & 18 \\
\hline & & 6 & 19 & 6 & 19 & 6 & 19 \\
\hline & & - & - & - & - & 4 & 23 \\
\hline & & - & - & - & - & 3 & 26 \\
\hline & & - & - & - & - & 2 & 29 \\
\hline & & - & - & - & - & 1 & 30 \\
\hline & 4 & - & - & - & - & 10 & 7 \\
\hline & & - & - & 5 & 8 & 5 & 8 \\
\hline & & - & - & - & - & 3 & 16 \\
\hline & & - & - & - & - & 2 & 22 \\
\hline & 5 & - & - & 5 & 3 & 5 & 3 \\
\hline & & - & - & - & - & 4 & 8 \\
\hline
\end{tabular}




\section{Sonuç ve Öneriler}

Hücresel üretim sistemlerinde ișçilerin önemli bir rolü olmasına rağmen üretim hücrelerinin olușturulması esnasında genellikle işçiler göz ardı edilmektedir. Bu çalışmada makine, parça ve işçilerin birlikte dikkate alındığı üç boyutlu hücre oluşturma problemi ele alınmıştır. Problemin çözümü için hücre dışı ve kullanılmayan eleman sayılarının eşzamanlı enküçüklendiği çok amaçlı matematiksel model genişletilmiş $\varepsilon$-kısıt yöntemi ile çözülmüş ve literatürde daha önce elde edilememiş baskın çözümlere ulaşılmıștır. Gelecekte daha büyük boyutlu problemlerin çözümü için çok amaçlı metasezgisel yöntemler geliştirilebilir.

\section{Araştırmacıların Katkısı}

$\mathrm{Bu}$ araştırmada; Feriştah Özçelik, literatürün taranması, matematiksel modelin geliştirilmesi, testlerin yapılması, makale metninin yazımı; Tuğba Saraç, literatürün taranması, matematiksel modelin geliştirilmesi, testlerin yapılması, makale metninin yazımı konularında katkı sağlamışlardır.

\section{Çıkar Çatışması}

Yazarlar tarafından herhangi bir çıkar çatışması beyan edilmemiştir.

\section{Kaynaklar}

Aalaei, A., Shavazipour, B.(2013). The tchebycheff norm for ranking dmus in cellular manufacturing systems with assignment worker.International Journal of Applied Operational Research, 3(3), 41-57. Erişim adresi:http://ijaor.com/article-1-241-en.pdf

Bagheri, F., Kermanshahi, M., Safaei, A. S., Paydar, M.M. (2019). Robust design of dynamic cell formation problem considering the workers interest.IJE TRANSACTIONS C: Aspects,32(12), 1790-1797. doi: https://dx.doi.org/10.5829/ije.2019.32.12c.12

Bootaki, B., Mahdavi, I., Paydar, M. M.(2014). A hybrid GA-AUGMECON method to solve a cubic cell formation problem considering different worker skills. Computers \& Industrial Engineering, 75, 3140. doi: https://doi.org/10.1016/j.cie.2014.05.022

Bootaki, B., Mahdavi, I., Paydar, M.M. (2016). New criteria for configuration of cellular manufacturing considering product mix variation.Computers \& Industrial Engineering, 98, 413-426. doi: https://doi.org/10.1016/j.cie.2016.06.021

Bouaziz, H., Berghida, M., Lemouari, A. (2020). Solving the generalized cubic cell formation problem using discrete flower pollination algorithm. Expert Systems with Applications, 150, 113345. doi:https://doi.org/10.1016/j.eswa.2020.113345

Buruk Sahin Y. \& Alpay S. (2016). A metaheuristic approach for a cubic cell formation problem. Expert Systems with Applications, 65, 40-51. doi: https://doi.org/10.1016/i.eswa.2016.08.034

Fahmy, S.A. (2019). MILP model and a genetic algorithm for the integrated cell formation, layout and worker assignment problem. 2019 IEEE 10th International Conference on Mechanical and Intelligent Manufacturing Technologies, 117-121. Doi : https://doi.org/10.1109/ICMIMT.2019.8712016

Feng, H., Da, W., Xi, L., Pan, E., Xia, T. (2017). Solving the integrated cell formation and worker assignment problem using particle swarm optimization and linear programming.Computers \& Industrial Engineering, 110, 126-137 .doi: https://doi.org/ $\underline{10.1016 / j . c i e .2017 .05 .038}$

Gökdaş, H., Özçelik, F.(2020), Kübik hücre oluşturma problemi için arı algoritması.Pamukkale Üniversitesi Mühendislik Bilimleri Dergisi, 26(4), 812-822. Erişim adresi: http://pajes.pau.edu.tr/en/jvi.aspx?pdir= pajes\&plng=eng\&un=PAJES-85125

Mahdavi, I., Aalaei, A., Paydar, M.M., Solimanpur, M. (2012). A new mathematical model for integrating all incidence matrices in multi-dimensional cellular manufacturing system. Journal of Manufacturing Systems, 31, 214- 223. doi: https://doi.org/ 10.1016/j.jmsy.2011.07.007

Mavrotas G. (2009). Effective implementation of the $\varepsilon^{-}$ constraint method in Multi-Objective Mathematical Programming problems.Applied Mathematics and Computation, 213, 455-465. doi: https://doi.org/ 10.1016/j.amc.2009.03.037

Mehdizadeh, E., Niaki, S.V.D., Rahimi, V.(2016). A vibration damping optimization algorithm for solving a new multi-objective dynamic cell formation problem with workers training.Computers \& Industrial Engineering, 101, 35-52. doi:https://doi.org/10.1016/j.cie.2016.08.012

Min, H., \& Shin, D. (1993). Simultaneous formation of machine and human cells in group technology: A multiple objective approach.International Journal of Production Research, 31(1), 2307-2318. doi:https://doi.org/10.1080/00207549308956859 